\title{
Biosynthesis of Gold Nanoparticles Using Pleurotus ostreatus extract with Their Electrochemical Activity of Detection of Carbendazim in vegetable
}

\author{
Wei Wang ${ }^{1}$,Fangjie Yao ${ }^{1, *}$, Daxiang Wang ${ }^{4}$, Xudan Zhou ${ }^{1}$, Xiaomei Wang ${ }^{2}$, Chengai Zhao ${ }^{3}$, \\ Ming Fang ${ }^{1}$ and Jing Cai ${ }^{1}$ \\ ${ }^{1}$ College of Horticulture, Jilin Agricultural University, No.2888 Xincheng St, Changchun, Jilin, \\ 130118, P.R. China \\ ${ }^{2}$ College of Agricultural, Jilin Agricultural University, No.2888 Xincheng St, Changchun, Jilin, \\ 130118, P.R. China \\ ${ }^{3}$ Collage of Resources and Environment. Jilin Agricultural University, No.2888 Xincheng St, \\ Changchun, Jilin, 130118, P.R. China \\ ${ }^{4}$ Xinyang of Henan Province Hydroglogy and Water Resources Survey Bureau, Xinyang, Henan, \\ P.R.China, \\ "E-mail: yaofangjie_228@qq.com
}

doi: $10.20964 / 2017.02 .23$

Received: 28 October 2016 / Accepted: 5 December 2016 / Published: 30 December 2016

\begin{abstract}
Biosynthesis has attracted numerous attentions recently in the field of nanomaterial synthesis owing to its non-toxicity and environmental protection. Herein, AuNPs were successfully prepared by biosynthesis with Pleurotus ostreatus produced laccase as reducing agent. The formation of metallic $\mathrm{Au}$ was confirmed by both UV-vis spectroscopy, X-ray diffraction (XRD) and X-ray photoelectron spectroscopy (XPS). As shown form the results of scanning electron microscopy, the mean size of the biosynthesized AuNPs were $47 \mathrm{~nm}$. The biosynthesized AuNPs were then applied for the modification of screen printed electrode. The electrochemical sensor constructed with AuNPs/SPE electrode demonstrated remarkable performance towards the determination of carbendazim in vegetable.
\end{abstract}

Keywords: Biosensor; Carbendazim; Electrode modification; Pleurotus ostreatus; Au NPs

\section{$\underline{\text { FULL TEXT }}$}

(C) 2017 The Authors. Published by ESG (www.electrochemsci.org). This article is an open access article distributed under the terms and conditions of the Creative Commons Attribution license (http://creativecommons.org/licenses/by/4.0/). 